cyclothiazide to inhibit receptor desensitization ${ }^{14,20-22}$. In the presence of $50 \mu \mathrm{M}$ cyclothiazide, which prolonged non-NMDA e.a.cs by fivefold, glial depolarization, hydroxyaspartate and $\mathrm{Li}^{+}$ further prolonged non-NMDA e.a.cs (Fig $4 a-c$ ). In $7 / 12$ cell pairs treated with cyclothiazide, hydroxyaspartate combined with glial depolarization slowed non-NMDA e.a.c. decays more than glial depolarization alone $(27 \pm 5 \%$ increase in the time constant of e.a.c. decay ( $\left.\tau_{\text {decay }}\right), n=7$ ), suggesting that hydroxyaspartate-sensitive neuronal uptake also contributes to glutamate removal.

The ability of cyclothiazide to prolong e.a.cs suggests that desensitization participates in evoked e.a.c. termination ${ }^{20}$. However, cyclothiazide may also alter the channel closing rate, as suggested by an increase in the apparent affinity of non-NMDA receptors ${ }^{21,22}$. Our data do not allow us to determine which of these changes underlies prolongation of e.a.us and the dependence of the decay on uptake. If glutamate uptake is the primary means of rapidly clearing glutamate from the synaptic cleft, there would probably be a decreasing dependence of e.a.c. decay on uptake as the apparent affinity of receptors is increased, a prediction contrary to the results obtained with cyclothiazide (Fig. $4 a$ ). However, if diffusion rapidly clears most glutamate from the cleft, and uptake removes only residual glutamate (which would not normally activate receptors), then an apparent increase in affinity might lead to greater dependence of e.a.c. decay on uptake.

Autaptic responses mediated by NMDA receptors, which exhibit higher affinity for glutamate and slower desensitization than non-NMDA receptors ${ }^{19,23}$, were also prolonged by glial depolarization (Fig. 4d, e). Consistent with these results, hydroxyaspartate and $\mathrm{Li}^{+}$prolonged NMDA e.a.cs (THA: $\tau 1_{\text {decay }}$ (the first time constant of decay of the NMDA component of e.a.cs) $=75 \pm 24 \%$ increase, $\tau 2_{\text {dccay }}$ (the second exponential time constant $)=68 \pm 28 \%$ increase, $n=5 ; \mathrm{Li}^{+}: \tau 1_{\text {decay }}=$ $90 \pm 23 \%$ increase, $\tau 2_{\text {decay }}=23 \pm 16 \%$ increase, $n=7$ ). These results suggest that postsynaptic receptor properties, diffusion and glutamate uptake all contribute to shaping evoked e.a.cs.

Our results support emerging concepts of glia as participants in neurotransmission ${ }^{24,25}$. These studies suggest that one reason for the lack of effect of uptake inhibition on non-NMDA e.p.s.c. decays (Fig. $4 a$ and refs 17,18) is that postsynaptic receptor properties dictate the time course of non-NMDA e.p.s.cs, despite the prolonged presence of glutamate during uptake inhibition. Further study should reveal whether the prolongation of synaptic $[\mathrm{Glu}]_{0}$ by uptake inhibition can modulate neurotransmission by altering postsynaptic receptor desensitization and/or presynaptic release ${ }^{26}$. Similarly, by regulating tonic ambient glutamate levels, uptake may be important in long-term synaptic plasticity and in glutamate toxicity.

\footnotetext{
Received 27 August; accepted 7 December 1993.

1. Wyllie, D. J. A., Mathie, A., Symonds, C. J. \& Cull-Candy, S. G. J. Physiol., Lond. 432, $235-$ 258 (1991).

2. Barres, B. A. J. Neurosci. 11, 3685-3694 (1991)

3. Brew, H. \& Attwell. D. Nature 327 707-709 (1987).

4. Barbour, B., Brew, H. \& Attwell, D. J. Physiol., Lond. 436, 169-193 (1991).

5. Szatkowski, M., Barbour, B. \& Attwell, D. Nature $\mathbf{3 4 8} 443-446(1990)$.

6. Segal, M. M. J. Neurophysiol. 65, 761-770 (1991).

7. Bekkers, J. M. \& Stevens, C. F. Proc. natn. Acad. Sci. U.S.A. 88, 7834-7838 (1991).

8. Bridges, R. J., Stanley, M. S., Anderson, M. W., Cotman, C. W. \& Chamberlin, A. R. J. med Chem. 34, 717-725 (1991)

Chem. 34, 717-725 (1991).
G. Hille, B. J.gen. Physiol. 59, 637-658 (1972).

10. Karwoski, C. J., Lu, H.-K. \& Newman, E. A. Science 244, 578-580 (1989).

10. Karwoski, C. J., Lu, H.-K. \& Newman, E. A. Science 244, 578-580
11. Korn, H. \& Faber, D. S. Trends Neurosci. 14, 439-445 (1991).

12. Katz B. \& Miledi R. Proc. R. Soc. B161, 496-503 (1965).

13. Harrison, N. L. J. Physiol., Lond. 422, 433-446 (1990).

14. Zorumski, C. F., Yamada, K. A., Price, M. T. \& Olney, J. W. Neuron 10, 61-67 (1993).

15. Clements, J. D., Lester, R. A., Tong, G., Jahr, C. E. \& Westbrook, G. L. Science 258, 1498 1501 (1992).

16. Eccles, J. C. \& Jaeger, J. C. Proc. R. Soc. B148, 38-56 (1957).

17. Hestrin, S., Sah, P. \& Nicoll, R. A. Neuron 5, 247-253 (1990).

17. Hestrin, S., Sah, P. \& Nicoll, R. A. Neuron 5, 24
18. Sarantis, M. et al. Neuron 11, 541-549 (1993).

19. Patneau, D. K. \& Mayer, M. L. J. Neurosci. 10, 2385-2399 (1990).

20. Trussell, L. O., Zhang, S. \& Raman, I. M. Neuron 10, 1185-1196 (1993)

21. Patneau, D. K., Vycklicky, L. Jr \& Mayer, M. L. J. Neurosci. 13, 3496-3509 (1993)

22. Yamada, K. A. \& Tang, C.-M. J. Neurosci. 13, 3904-3915 (1993).

23. Lester, R. A. \& Jahr, C. E. J. Neurosci. 12, 635-643 (1992).
}

24. Cornell-Bell, A. H., Finkbeiner, S. M., Cooper, M. S. \& Smith, S. J. Science 247, 470-473 (1990).

25. Murphy, T. H., Blatter, L. A., Wier, W. G. \& Baraban, J. M. J. Neurosci. 13, 2672-2679 (1993).

26. Forsythe, I. D. \& Clements, J. D. J. Physiol., Lond. 429, 1-16 (1990).

27. Lucero, M. T. \& Pappone, P. A. J. gen. Physiol. 95, 523-544 (1990)

28. Stephens, G. J., Djamgoz, M. B. A. \& Wilkin, G. P. Receptors Channels 1, 39-52 (1993)

29. Sather, W., Dieudonne, S., MacDonald, J. F. \& Ascher, P. J. Physiol., Lond. 450, 643-672 (1992).

30. Colquhoun, D., Jonas, P. \& Sakmann, B. J. Physiol., Lond. 458, 261-287 (1992).

ACKNOWLEDGEMENTS. We thank J. Que and A. Benz for technical assistance, and R. Wilkinson, J. Huettner, J. H. Steinbach, K. Yamada, L. Thio, K. Kato, Y. Izumi and D. B. Clifford for discussion. This work was supported by grants from NIMH and the Bantly Foundation.

\section{Understanding the controversy over the identity of EDRF}

\section{Martin Feelisch, Marc te Poel, Rubén Zamora, Andreas Deussen* \& Salvador Moncada $\dagger$}

Department of Pharmacology, Schwarz Pharma AG,

Monheim 40789, Germany

* Center of Physiology, Heinrich-Heine-University,

Dusseldorf 40225, Germany

$\dagger$ Wellcome Research Laboratories, Beckenham, Kent BR3 3BS, UK

ThiRTEEN years after its discovery ${ }^{1}$, there is still controversy over the chemical identity of endothelium-derived relaxing factor (EDRF). Although pharmacological and chemical evidence indicates that EDRF is nitric oxide ${ }^{2}$, other candidates, including $S$ nitrosocysteine $e^{3,4}$, dinitrosyl-iron-cysteine complex ${ }^{5}$, nitroxyl ${ }^{6}$ and hydroxylamine ${ }^{7}$, have been proposed to account for the vasorelaxant properties of EDRF. Such diverse compounds should differ in their stability and in reactivity with oxyhaemoglobin and with redox-active nucleophiles such as thiols. Here we use a bioassay to compare the pharmacodynamic profiles of these and other compounds with those of nitric oxide and EDRF. We find that some $S$-nitrosothiols, dinitrosyl-iron-cysteine complex, sodium nitroxyl and hydroxylamine can be eliminated as candidates as they are more stable than EDRF and less susceptible to inhibition by oxyhaemoglobin. Co-infusion of cysteine revealed major differences between the remaining candidates because it reduced the effect of authentic nitric oxide and EDRF on the bioassay tissues but enhanced the survival of $S$-nitrosocysteine and $S$-nitrosocysteamine. Our results further support the evidence that EDRF, the pharmacological entity described by Furchgott and Zawadzki ${ }^{\text {, }}$ is nitric oxide.

Comparison of the relaxing actions of various EDRF candidates in a cascade superfusion bioassay system comprising three precontracted de-endothelialized rabbit aortic strips ${ }^{8}$ showed that nitric oxide was 3-10-fold less potent than $S$-nitrosocysteine, $S$-nitrosocysteamine and $S$-nitrosoglutathione when infused over the tissues for $1 \mathrm{~min}$ at equimolar concentrations (Fig. 1). The apparent greater potency of the $S$-nitrosothiols could be attributable to the breakdown of nitric oxide to inactive products, whereas $S$-nitrosothiols break down to the active nitric oxide on passage down the cascade. D- and L-S-nitrosocysteine were equally effective, ruling out the involvement of specific $S$ nitrosothiol receptors ${ }^{9}$ in the mediation of vascular relaxation. On a molar basis, hydroxylamine and sodium nitroxyl were 5 10-fold and 1,000-fold less effective, respectively, than nitric oxide. Dinitrosyl-iron-cysteine complex (DNIC) was equipotent to nitric oxide but had a considerably longer duration of action (Fig. 1), possibly because it can lodge in the tissue, as does Roussin's Black salt ${ }^{10}$. Moreover, the bioassay tissues did not recover their initial tone after addition of higher concentrations of DNIC, whereas the effect of a 30 -min infusion of nitric oxide matching the potency of DNIC on the uppermost tissue was reversed when the infusion ceased (not shown).

Table 1 shows that the greater stability of DNIC, sodium nitroxyl and hydroxylamine, and their different susceptibility 
FIG. 1 Comparison of the relaxing activity of authentic nitric oxide with that of various S-nitrosothiols, sodium nitroxyl ( $\mathrm{NaNO}$ ) and hydroxylamine. The bioassay system comprised three rabbit endothelium-denuded aortic strips arranged in a cascade and superfused with oxygenated Krebs buffer (in $\mathrm{mM}: \mathrm{NaCl}, 126.8 ; \mathrm{KCl}, 5.9 ; \mathrm{MgCl}_{2}, 1.2 ; \mathrm{NaH}_{2} \mathrm{PO}_{4}, 1.2$; $\mathrm{CaCl}_{2}, 2.5 ; \mathrm{NaHCO}_{3}, 30.0$; glucose, 5.0; this was supplemented with $1 \mu \mathrm{M}$ indomethacin) at $5 \mathrm{ml} \mathrm{min}{ }^{-1}$. Strips were submaximally contracted with either phenylephrine $(200-300 \mathrm{nM})$ or the stable thromboxane $A_{2}$ mimetic $U 46619(30-50 \mathrm{nM})$ and separated from one another by a transit time of $3 \mathrm{~s}$. GTN, Glyceryl trinitrate; GSNO, Snitrosoglutathione; CysaNO, S-nitrosocysteamine; CysNO, Snitrosocysteine.

METHODS. Aqueous solutions of nitric oxide were prepared as described previously ${ }^{19}$. S-nitrosothiols were synthesized daily by acid-catalysed Snitrosation of the respective thiols with sodium nitrite at $2{ }^{\circ} \mathrm{C}$. Isolation of solid compound was achieved by acetone precipitation, extensive washing of the collected crystals with ice-cold acetone and diethyl ether and drying in a stream of argon in the dark. Identity was verified by UV/ visual spectrometry, mass spectrometry and HPLC immediately after preparation. Stock solutions in de-aerated ice-cold citrate buffer, $\mathrm{pH} 2.2$, were protected from light, and all dilutions were made in argon-gassed ice-cold saline immediately before use. The vehicle alone had no effect on the bioassay. DNIC was prepared as described previously ${ }^{20}$, and frozen stock solutions with a molar ratio of $\mathrm{Fe}^{2+}$ : cysteine of 1:20 were thawed and diluted in ice-cold saline just before use. Sodium nitroxyl was prepared by bubbling nitric oxide into a solution of sodium in liquid ammonia ${ }^{21}$ and dissolved in argon-gassed saline. Compounds were applied as 1-min infusions using gas-tight syringes. The delay time between the infusion site and the uppermost bioassay tissue was $0.5 \mathrm{~s}$. A 1-min infusion of $50 \mathrm{nM}$ glyceryl trinitrate served as an internal standard. Solutions were protected from light and delivered through stainless-steel tubing to prevent oxidative decomposition. The medium perfusing the assay tissues was maintained at $38 \pm 0.2^{\circ} \mathrm{C}$. The half-life of each compound was estimated by comparing the maximal relaxation obtained on the first bioassay tissue with that obtained on the second and third strip, taking into account a transit time of $3 \mathrm{~s}$ from tissue to tissue. The molar concentration of DNIC is expressed as the concentration of nitric oxide in the complex. The tracings shown are typical of five similar experiments.

to inhibition by oxyhaemoglobin, rule them out as potential candidates for EDRF. Other $S$-nitrosylated compounds tested (L-homocysteine, $N$-acetyl-DL-cysteine, glutathione, $N$-acetylDL-penicillamine and human serum albumin) were also considerably more stable than EDRF on passage down the cascade (not shown).

Only $S$-nitrosocysteine and $S$-nitrosocysteamine had a biological profile similar to that of nitric oxide on these bioassay tissues; however, the use of either L- or D-cysteine distinguished between the actions of these compounds. Infusion of cysteine over the detector tissues completely abrogated the relaxing effect of basally released EDRF from the rabbit aorta, as well as from endothelial cells in culture. Furthermore, cysteine inhibited the relaxing action both of authentic nitric oxide and of EDRF released by the cells following stimulation with bradykinin (Fig. 2). In contrast, the relaxing action of the $S$-nitrosothiols was unaffected on the first tissue and was markedly enhanced on the lower tissues, indicating stabilization of these compounds. This discriminatory effect of cysteine was dependent on its concentration, starting at $\sim 1 \mu \mathrm{M}$ and becoming optimal at 5$10 \mu \mathrm{M}$. Concentrations of cysteine higher than $100 \mu \mathrm{M}$, in contrast, potentiated the effects of EDRF, nitric oxide and $S$ nitrosocysteine. Figure 2 shows the effect of a fixed concentration of L-cysteine $(5 \mu \mathrm{M})$ on equipotent concentrations of EDRF, nitric oxide, $S$-nitrosocysteine and $S$-nitrosocysteamine, so that the ratio between thiol and the active component of each EDRF candidate was constant.

The effects of increasing concentrations of L-cysteine on the dilator response of rat isolated aortic rings in organ baths to equipotent concentrations of nitric oxide and $S$-nitrosocysteine are shown in Fig. 3. L-Cysteine caused a concentration-dependent enhancement of both the magnitude and duration of the relaxation elicited by $S$-nitrosocysteine. In contrast, the action of nitric oxide was reduced at concentrations of L-cysteine up to

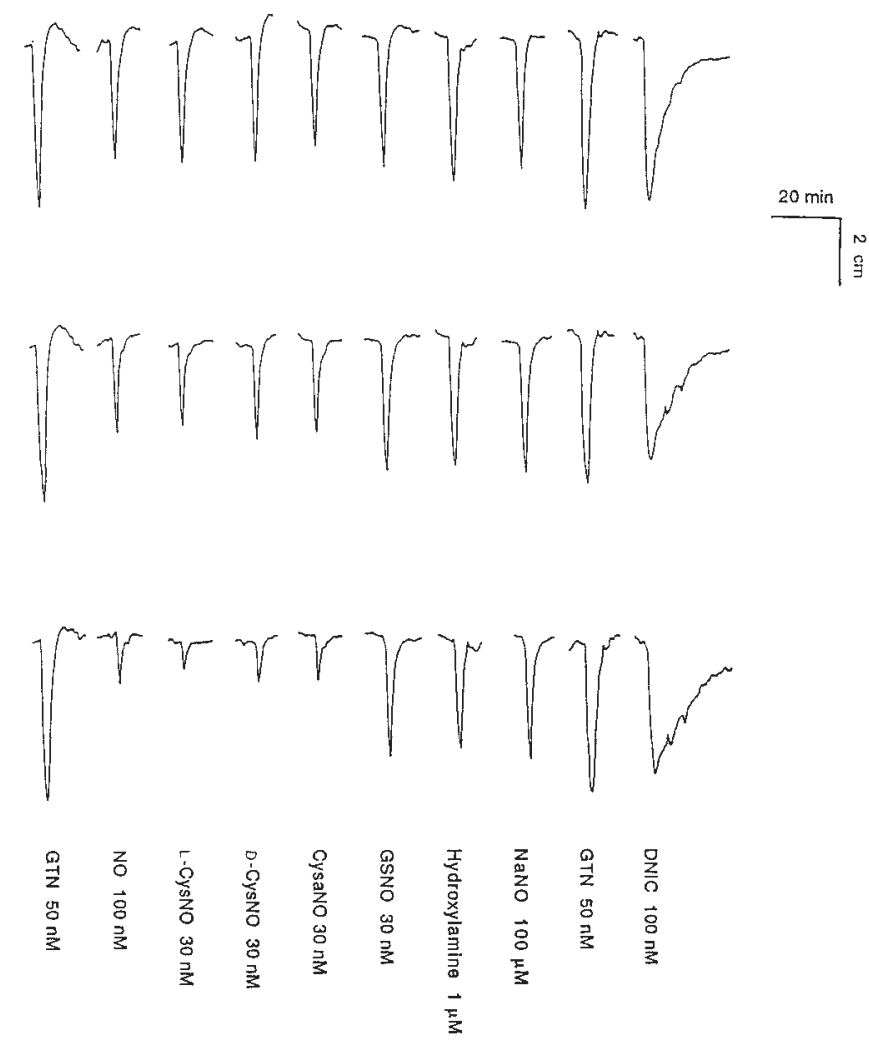

TABLE 1 Comparison of half-lives and sensitivity to inhibition by oxyhaemoglobin for some EDRF candidates

\begin{tabular}{lcc}
\hline \multicolumn{1}{c}{ Compound } & $\begin{array}{c}\text { Half-life in } \\
\text { bioassay cascade (s) }\end{array}$ & $\begin{array}{c}\text { Oxyhaemoglobin } \\
\mathrm{IC}_{50}(\mathrm{nM})\end{array}$ \\
EDRF & $3-5$ & 25 \\
Nitric oxide & $3-5$ & 25 \\
S-nitrosocysteine & $4-6$ & 40 \\
S-nitrosocysteamine & $4-6$ & 40 \\
DNIC & $\gg$ EDRF $^{*}$ & $>100$ \\
Hydroxylamine & $\gg$ EDRF* $^{*}$ & $>300$ \\
Sodium nitroxyl & $\gg$ EDRF* $^{*}$ & $>300$ \\
\hline
\end{tabular}

$1 \mathrm{C}_{50}, 50 \%$ inhibitory concentration.

* Half-life not measurable as there was no loss of activity during passage down the bioassay cascade.

$100 \mu \mathrm{M}$. At higher concentrations, however, L-cysteine (1 mM) greatly enhanced the nitric oxide-induced relaxation, so that it was equivalent to that of $S$-nitrosocysteine in the presence of this concentration of $\mathrm{L}$-cysteine, indicating that under these conditions $\sim 10 \%$ of the nitric oxide applied was converted to $S$ nitrosocysteine.

Thus, the use of cysteine reveals major differences between those EDRF candidates not ruled out by potency, stability and reactivity with oxyhaemoglobin. Our data agree with a previous report that EDRF released by acetylcholine from endothelial cells behaves like nitric oxide and not like $S$-nitrosocysteine ${ }^{11}$. There are various ways in which cysteine may inhibit the relaxant effects of EDRF and nitric oxide. Reaction between nitric oxide and cysteine to form $S$-nitrosocysteine ${ }^{12}$ is an unlikely possibility as this would lead to enhanced activity on the lower bioassay tissues, which was not observed. The generation of superoxide $\left(\mathrm{O}_{2}^{-}\right)$by cysteine ${ }^{13}$, could account for the enhanced destruction of nitric oxide because, in isolated aortic rings in organ baths, superoxide dismutase almost completely reversed, and pyrogallol, a generator of $\mathrm{O}_{2}^{-}$(ref 14), mimicked in a superoxidedismutase-reversible manner the inhibitory effect of L-cysteine on nitric oxide-mediated relaxation ( $n=3$; not shown). Conver- 

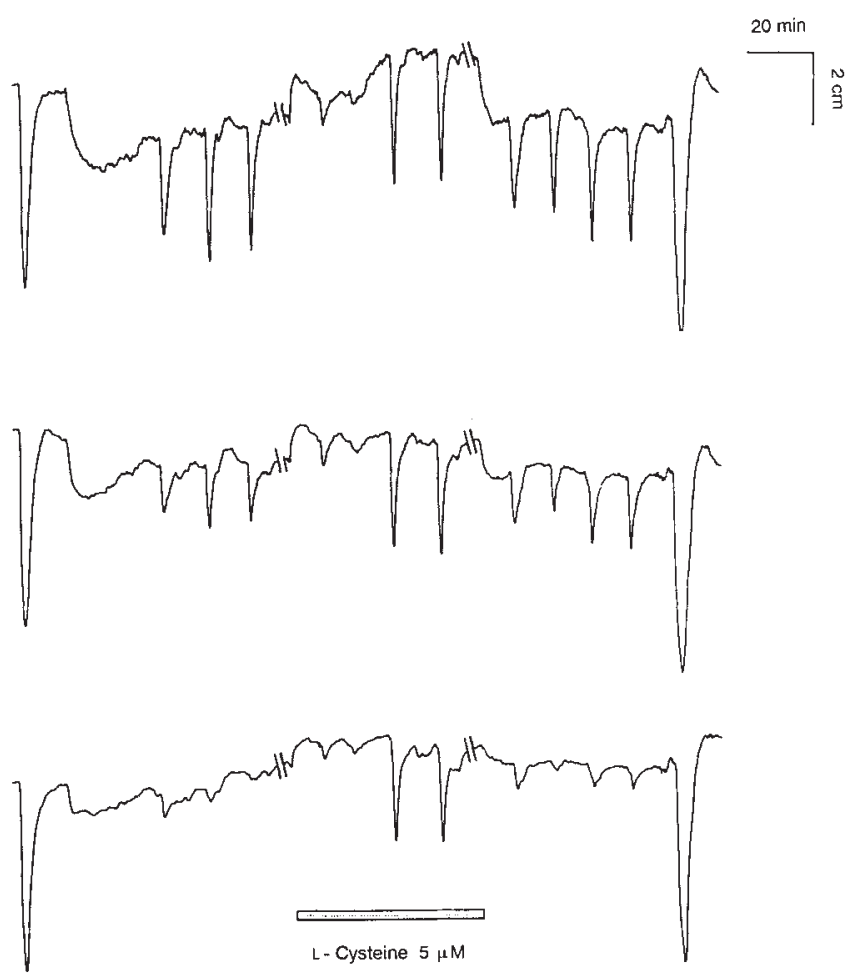

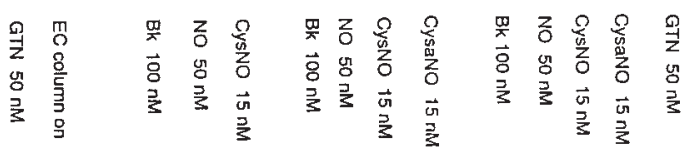

FIG. 2 The effect of L-cysteine on the relaxing actions of authentic nitric oxide, S-nitrosocysteamine (CysaNO), S-nitrosocysteine (CysNO) and EDRF released from endothelial cells in culture. Endothelial cells were isolated from porcine thoracic aorta, cultured on microcarrier beads as described previously and packed into a water-jacketed chromatography column ${ }^{22}$, the outlet of which was separated from the uppermost bioassay strip by a delay of $0.5 \mathrm{~s}$. When the bioassay cascade was perfused with effluent from the column ('EC column on') there was an immediate loss of tissue tone due to basal release of EDRF. Stimulated release of EDRF from the cells was achieved by a 1-min infusion of bradykinin $(\mathrm{Bk} ; 100 \mathrm{nM})$. L-Cysteine $(5 \mu \mathrm{M})$ was applied directly over the bioassay tissues, causing an immediate rise in tone which was reversed when the infusion was terminated. The tracing shown is representative of five experiments with similar results. EDRF released by acetylcholine $(0.3 \mu \mathrm{M})$ from an endothelium-intact segment of rabbit thoracic aorta gave the same bioassay profile in the presence and absence of L-cysteine as did that released from endothelial cells ( $n=3$, not shown).

sion of nitric oxide to another oxidation state $\left(\mathrm{NO}^{+}\right.$or $\left.\mathrm{NO}^{-}\right)$ may occur in the presence of cysteine. Recent evidence suggests that $\mathrm{NO}^{+}$, as such, is not a dilator, although a small proportion may be reduced spontaneously to nitric oxide ${ }^{15}$. Although $\mathrm{NO}^{-}$ has been reported to possess potent vasodilator activity ${ }^{16}$, our results using sodium nitroxyl show that it is only relaxant at very high concentrations, suggesting that $\mathrm{NO}^{-}$itself may not have been the species responsible for the vascular relaxation reported recently ${ }^{16}$. There is no evidence for direct chemical trapping of nitric oxide by cysteine, although this cannot be ruled out.

The enhancement of $S$-nitrosothiol activity by cysteine may be due to chemical stabilization. In spectrophotometric studies we found that the half-life of $S$-nitrosocysteine was dependent on the starting concentration of the nitrosothiol, the buffer composition and transition metal contamination of the water used. The half-life of $30 \mu \mathrm{M} S$-nitrosocysteine (as estimated by the loss

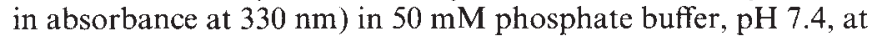
$37^{\circ} \mathrm{C}$ was $0.31 \pm 0.05 \mathrm{~min} \quad(n=4)$. Addition of L-cysteine

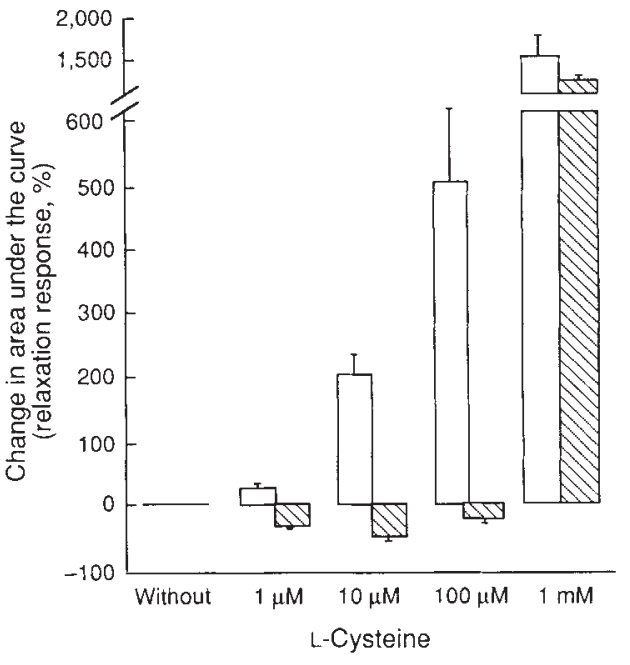

FIG. 3 Effect of different concentrations of L-cysteine on the relaxation to nitric oxide $(\mathbb{W})$ and S-nitrosocysteine $(\square)$ of rat endothelium-intact isolated aortic rings in an organ bath. The tissues were precontracted with $200 \mathrm{nM}$ phenylephrine and the response to equipotent concentrations of nitric oxide $(3 \mu \mathrm{M})$ and S-nitrosocysteine $(300 \mathrm{nM})$ was determined in the presence of increasing concentrations of L-cysteine added to the organ bath $5 \mathrm{~min}$ before addition of either compound. A single concentration of L-cysteine was used for each tissue and its effects on both vasodilators were compared. At concentrations of L-cysteine between $1 \mu \mathrm{M}$ and $100 \mu \mathrm{M}$ there was a marked difference in its effect on nitric oxide and S-nitrosocysteine mediated relaxation. However, at $1 \mathrm{mM}$, L-cysteine potentiated the relaxant effects of both compounds. Results shown are means \pm s.e.m. of three separate experiments.

$(10 \mu \mathrm{M}-100 \mathrm{mM})$ increased the stability of $S$-nitrosocysteine in a concentration-dependent manner, so that, at a molar ratio of $S$-nitrosocysteine to L-cysteine identical to that in the cascade experiments $(1: 333)$, the half-life of $30 \mu \mathrm{M} S$-nitrosocysteine was $36.9 \pm 3.7 \mathrm{~min}(n=4)$. EGTA and EDTA mimicked the effects of L-cysteine, suggesting that the stabilization of $S$ nitrosocysteine is probably due to the ability of thiols to complex metal ions present in the buffer solution, assuming that metal ion catalysis is the predominant pathway for the release of nitric oxide from $S$-nitrosothiols ${ }^{17}$.

We suggest that the discriminatory effect of cysteine on nitric oxide and $S$-nitrosothiols is due to its ability both to generate $\mathrm{O}_{2}^{-}$and to complex metal ions. Its $-\mathrm{SH}$ moiety probably confers these properties, as we observed similar effects with L-homocysteine, glutathione and human serum albumin (not shown). Because free sulphydryl groups can also react with oxidized forms of nitric oxide, this explains the paradoxical effect of thiols, as at low concentrations they will act as inactivators and at high concentrations, via $S$-nitrosation, as carriers for nitric oxide. The physiological concentration of thiols is of the order of $0.1-1 \mathrm{mM}^{18}$. In all classical bioassay systems for EDRF, thiol availability is limited, and this, as is known for oxygen concentration, has a bearing on the pharmacological half-life of EDRF. Moreover, the half-life and fate of nitric oxide depend on its concentration and the fact that physiological concentrations of nitric oxide are in the nanomolar range will limit its reactivity with molecules such as amines, thiols and $\mathrm{O}_{2}^{-}$

Therefore, we would like to re-state that EDRF, as described by Furchgott and Zawadzki ${ }^{1}$, is nitric oxide. Furthermore, the molecule responsible for transmitting the biological information provided by the L-arginine-nitric oxide pathway is most probably also nitric oxide; however, any claims about physiology will require a clearer understanding of the reactivity of nitric oxide at low concentrations in physiological environments.

Receivęd 12 August; accepted 21 December 1993.

1. Furchgott, R. F. \& Zawadzki, J. V. Nature 288, 373-376 (1980). 
2. Palmer, R. M. J., Ferrige, A. G. \& Moncada, S. Nature 327, 524-526 (1987).

3. Myers, P. R., Minor, R. L. Jr, Guerra, R. Jr, Bates, J. \& Harrison, D. G. Nature 345, 161$163(1990)$.

4. Rubanyi, G. M., Johns, A., Harrison, D. \& Wilcox, D. Circulation (suppl.) 80, II-281 (abstr.) (1988).

5. Vanin, A. F. FEBS LETT. 289, 1-3 (1991)

6. Fukuto, J. M., Hszieh, R. \& Chiang, K. T. FASEB J. 6, A972 (abstr.) (1992).

7. Thomas, G. \& Ramwell, P. W. Biochem. biophys. Res. Commun. 164, 889-893 (1989).

8. Palmer, R. M. J., Ferrige, A. G. \& Moncada, S. Nature 327, 524-526 (1987).

9. Lewis, S. J. et al. FASEB J. 6, A1165 (abstr.) (1992).

10. Flitney, F. W. Megson, I. L., Flitney, D. E. \& Butter, A. R. Br. J. Pharmac. 107, 842-848 (1992).

11. Furchgott, R. F., Jothianandan, D. \& Khan, M. T. Jpn. J. Pharmac, 58, (Suppl. 2), 185P$191 P(1992)$

12. Stamler, J. S. et al. Proc. natn. Acad. Sci. U.S.A. 89, 444-448 (1992)

13. Misra, H. P. J. biol. Chem. 269, 2151-2155 (1974).

14. Moncada, S., Palmer, R. M. J. \& Gryglewski, R. J. Proc. natn. Acad. Sci. U.S.A. 83, 9164$9168(\mathbf{1 9 8 6 )}$

15. Zamora Pino, R. \& Feelisch, M. Endothelium 1, $\$ 69$ (abstr.) (1993).

16. Fukuto, J. M. Chiang, K., Hszieh, R., Wong P. \& Chaudhuri, G. J. Pharmac. exp. Ther. 263, $546-551(1992)$.

17. MCAninly, J., Williams, D. L. H., Askew, S. C., Butler, A. R. \& Russell, C. JCS chem. Commun 23, 1758-1759 (1993).

18. Jocelyn, P. C. Blochemistry of the SH Group (Academic, New York, 1972).

19. Feelisch, M. J. cardiovasc. Pharmac. 17, S25-S33 (1991)

20. Vedernikov, Y. P., Mordvintcev, P. I., Maienkova, I. V. \& Vanin, A. F. Eur. J. Pharmac. 221, 313-317 (1992).

21. Zintl, E. \& Harder, A. Chem. Ber. 66, 760-761 (1933).

22. Kelm, M. et al. Biochem. biophys. Res. Commun. 154, 236-244 (1988)

ACKNOWLEDGEMENTS. We thank A. F. Vanin for DNIC, D. Rees and Y.-C. Su for technica assistance, and A. Higgs for help in preparing the manuscript.

\section{$\mathrm{Ca}^{2+}$-induced tropomyosin movement in Limulus thin filaments revealed by three-dimensional reconstruction}

\section{William Lehman*, Roger Craig ${ }^{\dagger} \&$ Peter Vibert}

* Department of Physiology, Boston University School of Medicine, 80 East Concord Street, Boston, Massachusetts 02118, USA $\dagger$ Department of Cell Biology, University of Massachusetts Medical School, Worcester, Massachusetts 01655, USA

$\ddagger$ Rosenstiel Basic Medical Sciences Center, Brandeis University, Waltham, Massachusetts 02554, USA

THE steric model of muscle regulation holds that tropomyosin strands running along thin filaments move away from myosinbinding sites on actin when muscle is activated. Exposing these sites would permit actomyosin interaction and contraction to proceed. This compelling and widely cited model is based on changes observed in X-ray diffraction patterns of skeletal muscle following activation $^{1-3}$. Although analysis of $\mathrm{X}$-ray patterns can suggest models of filament structure, unambiguous interpretation is not possible. In contrast, three-dimensional reconstruction of thinfilament electron micrographs could, in principle, offer direct confirmation of the predicted tropomyosin movement, but so far tropomyosin in skeletal muscle has been resolved definitively only in the 'on' state but not in the 'off' state'. Thin filaments from the arthropod Limulus have a similar composition to those from vertebrate skeletal muscle ${ }^{5}$, and troponin-tropomyosin is distributed in both species with the same characteristic $38-\mathrm{nm}$ periodicity ${ }^{6}$. Limulus thin filaments activate skeletal muscle myosin ATPase at micromolar $\mathrm{Ca}^{2+}$ concentrations and confer a high calcium dependence on the enzyme. Arthropod and vertebrate troponin subunits form functional hybrids in vitro ${ }^{7}$ and the respective tropomyosins are functionally interchangeable ${ }^{8,9}$, arguing for a common mechanism of thin-filament-linked regulation in the two phyla. Here we report that tropomyosin is readily resolved in native filaments of troponinregulated Limulus muscle in both the 'on' and 'off' states, and demonstrate tropomyosin movement, providing support for the importance of steric effects in muscle activation. $a$

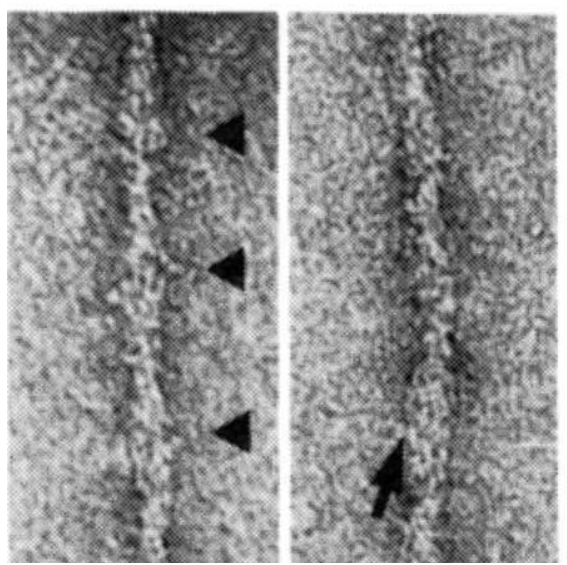

$b$

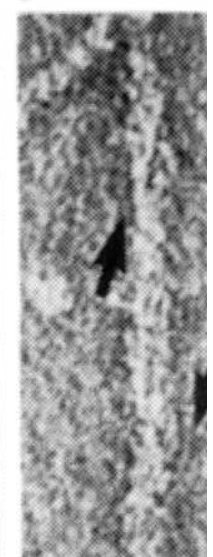

FIG. 1 Electron micrographs of Limulus thin filaments negatively stained with uranyl acetate: $a$, in EGTA, and $b$, in $\mathrm{Ca}^{2+}$; bulges repeating at 40 $\mathrm{nm}$ intervals (arrowheads) and narrow helically oriented strands (arrows) are indicated. Scale bar, $0.05 \mu \mathrm{m}$. ATPase was assayed ${ }^{7,8}$ on three preparations of thin filaments isolated ${ }^{5,6}$ for electron microscopy. Each fully activated rabbit skeletal muscle myosin (ATPase activity, $0.60 \pm 0.04 \mu \mathrm{mol} \mathrm{min}^{-1}$ per $\mathrm{mg}$ myosin); calcium sensitivity (per cent inhibition of ATPase on removal of $\mathrm{Ca}^{2+}$ ) was $92 \pm 1 \% \mathrm{Ca}^{2+}$ sensitivity was unaffected by dilution to the concentrations $\left(0.03-0.1 \mathrm{mg} \mathrm{ml}^{-1}\right.$ ) necessary for microscopy and was stable for several months, although only freshly prepared samples were used for negative staining ${ }^{21}$. Images were recorded using the Minimal Dose System of a JEOL $100 \mathrm{CX}$ electron microscope ${ }^{21}$ at a magnification of $\times 50,000$ and digitized on an Eikonix 1412 scanner for image analysis ${ }^{11}$.

Negatively stained Limulus thin filaments (Fig. 1) isolated in EGTA and either maintained in EGTA or treated with $\mathrm{Ca}^{2+}$ show the characteristic double-helical array of actin subunits and in addition frequently display periodic bulges repeating at 40-nm intervals (compare ref. 10). These bulges are presumably a manifestation of the large mass of Limulus troponin ${ }^{5}$ as they are not obvious in vertebrate filaments in which troponin has smaller mass. Limulus filaments also often exhibit elongated strands aligned with the long-pitch actin helices, which we have previously shown ${ }^{11}$ to be a reflection, at least in part, of extended tropomyosin molecules. In any given field, however, strands and periodic bulges are not always evident, possibly because of varied troponin subunit orientation or stain penetration.

Density maps (Figs 2,3) calculated from the averaged layerline data of ten filaments maintained in EGTA (Fig. 4) reveal actin monomers whose bi-lobed, two-domain shape and monomer-monomer connectivity are indistinguishable from those in reconstructions of negatively stained vertebrate smooth muscle thin filaments " and frozen hydrated skeletal filaments ${ }^{4}$. In addition, a longitudinally continuous strand of density follows successive actin monomers in contact with the extreme inner edge of their outer domains.

Density maps (Figs 2, 3) calculated from the averaged layer line data of six $\mathrm{Ca}^{2+}$-treated filaments (Fig. 4) reveal actin monomer shape and connectivity very similar to those seen in the EGTA-treated filaments. The elongated strand of density, however, is now located in a different position, closely associated with the inner domain of actin. Comparison of the EGTA and $\mathrm{Ca}^{2+}$ maps shows that the strand has moved azimuthally by $\sim 25^{\circ}$ about the actin helix axis. Statistical tests demonstrate that the $\mathrm{Ca}^{2+}$-induced strand rotation is significant at greater than the $99.5 \%$ confidence level. Although there is partial overlap in the strand position, the point of contact with actin is distinct in the two maps.

Tropomyosin, an elongated molecule ${ }^{12}$, is likely to make the major contribution to the strand observed in Limulus thin filaments. Troponin subunit $\mathrm{T}$ in vertebrates is also an asymmetric molecule that binds to tropomyosin ${ }^{13}$, and, by analogy, Limulus 